\title{
O sentido da visita domiciliária realizada por estudantes de medicina e enfermagem: um estudo qualitativo com usuários de unidades de saúde da família
}

\author{
The meaning of home visits conducted by medicine and nursing \\ students: a qualitative study with users of family health units
}

\author{
Maria José Sanches Marin ${ }^{1}$ \\ Romeu Gomes ${ }^{2}$ \\ Antonio Carlos Siqueira Junior ${ }^{3}$ \\ Cássia Regina Rodrigues Nunes ${ }^{4}$ \\ Cristina Peres Cardoso ${ }^{5}$ \\ Márcia Padovan Otani ${ }^{3}$ \\ Maria Yvette Moravcik ${ }^{6}$
}

\footnotetext{
${ }^{1}$ Disciplina de Enfermagem em Saúde Coletiva, Faculdade de Medicina de Marília. Av. Monte Carmelo 800, Bosque Marília. 17519-030 Marília SP. marnadia@terra.com.br ${ }^{2}$ Instituto Fernandes Figueira, Fundação Oswaldo Cruz

${ }^{3}$ Disciplina de Saúde Mental, Faculdade de Medicina de Marília

${ }^{4}$ Disciplina de Bioética, Faculdade de Medicina de Marília

${ }^{5}$ Disciplina de Enfermagem Pediátrica, Faculdade de Medicina de Marília

${ }^{6}$ Disciplina de Clínica Médica, Faculdade de Medicina de Marília
}

Abstract Home visits (HVs) are considered an important technology to comprehend and care for the population's health requirements. Therefore, they must be a part of the health professionals' education. This study seeks to analyze HVs performed by first-year medical and nursing students from the viewpoint of family health unit users. It is a qualitative study in which data are collected by means of semi-structured interviews with users who are visited by Marilia Medical School medical and nursing students. The interpretation of meaning method is used and is based on a hermeneutic-dialectic perspective. The users find it positive that the students go beyond the biological care of the body and focus on interpersonal interrelationships. Nevertheless, the users believe it is necessary to organize and plan HVs accordingly. It may thus be inferred that HVs elicit the interaction between humanized healthcare and its users. Planning and reinforcement of health actions must be continuously improved when planning and conducting home visits.

Key words Home visit, Healthcare, Teaching
Resumo A visita domiciliária (VD) é considerada uma importante tecnologia para a compreensão e para o cuidado às necessidades de saúde da população. Decorre daí a demanda de sua prática nos processos de formação de profissionais da saúde. Este estudo se propõe a analisar a ótica dos usuários de unidades de saúde da família sobre as $V D$ s realizadas por estudantes das séries iniciais de medicina e de enfermagem. Trata-se de um estudo de abordagem qualitativa, que utiliza, para coleta de dados, a entrevista semiestruturada realizada com usuários que receberam visitas dos estudantes de Enfermagem e de Medicina da Faculdade de Medicina de Marília. Para análise dos dados utiliza-se o método de interpretação de sentidos baseado na perspectiva hermenêutico-dialética. Os usuários apontam como positivo o fato de que a atuação dos estudantes vai além do cuidado com um corpo biológico, evidenciando a importância das relações interpessoais no contexto da atenção à saúde. Como limitação da VD, os usuários indicam a necessidade de sua maior organização e planejamento. Depreende-se que a VD amplia a interatividade entre o serviço de saúde e o usuário e se desenvolve conforme os princípios da humanização. No entanto, deve-se atentar à importância de um contínuo aperfeiçoamento no planejamento e na implementação das visitas domiciliárias.

Palavras chaves Visita domiciliária, Assistência à saúde, Ensino 


\section{Introdução}

No Brasil, a partir da década de 80 com o advento do Sistema Único de Saúde (SUS), é proposta como alternativa de mudança ao modelo de atenção básica à saúde a implantação, em todo território nacional, da Estratégia de Saúde da Família (ESF). Espera-se da equipe de saúde da família, ao atuar em uma área adscrita, que desenvolva ações de saúde dirigidas às famílias e ao seu ambiente, com ênfase nos aspectos preventivos, curativos e de reabilitação, articulados com outros setores que contribuam para a melhoria das condições de saúde ${ }^{1}$. A ESF elege, então, como ponto central, o estabelecimento de vínculo e a criação de laços de compromisso e de responsabilidade entre os profissionais de saúde e a população ${ }^{2}$.

Neste contexto, a Visita Domiciliária (VD) passa a ser compreendida como importante tecnologia no cuidado à saúde da família ${ }^{3}$, sendo apontada como eixo transversal que passa pela universalidade, integralidade e equidade. Junto à compreensão, destaca-se a VD como prática emancipadora, que proporciona aos profissionais importante espaço para o exercício do diálogo, possibilitando a proximidade para o acompanhamento, o conhecimento e o reconhecimento das famílias em suas necessidades de saúde ${ }^{4,5}$.

Em recente resgate histórico sobre VD, no contexto da atenção à saúde, foi encontrado registro dessa prática desde a Grécia antiga. Ao longo de sua história, observa-se que, em alguns períodos, essa prática era realizada por profissional médico ou enfermeiro e em outros por pessoas leigas que recebiam treinamento para esse fim. O sentido de tais visitas sempre esteve mais voltado para controlar doenças e minimizar o sofrimento do que propriamente em promover a saúde, considerando o contexto social e a qualidade de vida ${ }^{6}$.

As visitas domiciliárias têm sido uma prática comum no campo do Serviço Social. Paugan ${ }^{7}$, ao estudar o tema da desqualificação social, problematiza as visitas a residências de famílias pobres que podem, por meio de rotulagens, trazer efeitos significativos no plano das identidades, além de possíveis transtornos e inconvenientes. Esse autor realizou um estudo na França, na década de 80 do século passado, momento em que o desemprego levou muitas pessoas a viverem em locais com aluguel de baixo custo ou em casas de parentes. Ele observou que as pessoas se sentiam estigmatizadas ao serem visitadas pelos assistentes sociais, além de terem que expor publicamente suas provações.
$\mathrm{Na}$ área da saúde, na literatura nacional da última década, encontram-se estudos ${ }^{4,8}$ que trazem considerações sobre a efetividade da VD no contexto da atenção básica à saúde, já que sua prática articula-se com a concomitante implantação da ESF.

$\mathrm{Na}$ busca de compreender a percepção de usuários acerca da VD, um estudo constatou sentimentos favoráveis relacionados às mesmas $\mathrm{e}$ como aspecto negativo a frequência esporádica e a duração reduzida. Considerou-se, portanto, que o sucesso desta estratégia refere-se não só ao fator técnico, mas principalmente da aproximação, diálogo e vínculo entre usuários, profissionais e serviços de saúde9.

Ao ser analisada a efetividade da VD, enquanto prática que atende ao princípio da integralidade e de promoção da autonomia dos usuários, em outro estudo ${ }^{4}$ se observou que a mesma é citada como instrumento de aproximação entre a equipe e os usuários e de promoção à saúde, embora admita que a concepção de integralidade ainda encontra-se restrita ao conhecimento do contexto que os usuários estão inseridos. Frente a esta constatação, se reconhece a necessidade de investimentos na reorientação das práticas profissionais e na formação de profissionais de saúde.

$\mathrm{Na}$ descrição das facilidades e dificuldades na realização da VD, foi observado o desenvolvimento de efetiva interação, vínculo e reflexão junto às famílias em relação às necessidades de saúde sentidas por eles além do reconhecimento da efetividade dos serviços de saúde. Revela-se, no entanto, que o horário de trabalho, os afazeres domésticos dos usuários, o tempo gasto pelo profissional na locomoção e a falta de integração entre as ações realizadas na VD e aquelas realizadas na unidade, dificultam a sua operacionalização"

Evidencia-se também, ao buscar o reconhecimento das dificuldades e facilidades da prática da VD realizada pelos profissionais da ESF, que por meio dela ocorre ampliação do acesso aos cuidados, vínculos e humanização da atenção à saúde. Em contrapartida elegem-se como limites a concentração de procedimentos clínicos-educativos direcionados aos indivíduos ${ }^{10}$.

Embora a VD feita pelos profissionais da equipe de saúde aos usuários esteja revestida de alguns limites, sobressai nos mencionados estudos a sua adequação quando se pretende a implementação de um modelo de atenção à saúde, com vistas à melhoria da qualidade de vida, com ênfase na vigilância da saúde.

A VD possibilita maior aproximação dos profissionais com os usuários e amplia o reconheci- 
mento do seu contexto de vida, condição básica para o cuidado integral. Desta forma, mesmo que algumas evidências demonstrem que a ESF ainda não tenha se desenvolvido suficientemente na construção de um novo modelo de atenção, é inegável a sua fortaleza enquanto proximidade usuário/equipe. Acrescenta-se que na ESF, quando os usuários adentram a unidade seja qual for a sua necessidade, toda a equipe já é capaz de reconhecer significativos aspectos da sua singularidade.

Se reconhece a VD como um instrumento de atenção à saúde capaz de fortalecer a ampliação do olhar sobre as necessidades de saúde das pessoas, famílias e comunidade, subentende-se que a formação dos profissionais de saúde precisa ser modificada em consonância com esta modalidade de atenção.

A perspectiva de formar profissionais com visão ampliada para as necessidades de saúde da população também está prevista nas diretrizes do SUS e tem feito parte do cotidiano das instituições formadoras e dos serviços de saúde, que vêm empenhando contínuo esforço vislumbrando modificar o atual modelo de atenção.

Neste contexto, a Faculdade de Medicina de Marília (Famema), há mais de uma década, vem implementando nos seus cursos de Enfermagem e Medicina um currículo integrado e pautado em metodologias ativas de aprendizagem, pressupondo o processo de aprendizagem a partir da vivência da prática profissional. Esta proposta de currículo está pautada no conceito de integralidade do cuidado, sob a ótica das necessidades de saúde e de uma educação transformadora, crítica e reflexiva, estimulando a produção de conhecimento, promovendo a reflexão sobre a prática e, consequentemente, sua transformação.

Nessa faculdade, desde as primeiras séries dos cursos, os estudantes realizam a Unidade de Prática Profissional (UPP), por meio de sua inserção em Unidades de Saúde da Família (USF). No cenário real, os estudantes reconhecem as necessidades de saúde das pessoas, famílias e comunidade a partir da realização de visitas domiciliares às famílias e participação no processo de trabalho da equipe. Neste contexto, problematizam-se as necessidades de saúde da pessoa/família, formula-se o problema de saúde e elabora-se um plano de cuidado que é implementado e avaliado pelos estudantes de forma articulada com a equipe.

A VD, assim, tem-se constituído na forma de colocar o estudante em contato com o contexto de vida das pessoas, permitindo uma visão ampliada dos determinantes do processo saúdedoença, incluindo as condições socioeconômicas, as ambientais e as de saúde física e emocional. Além disso, o desenvolvimento de atividades em cenários reais implica tanto na aprendizagem como no cuidado efetivo e integral das pessoas, famílias e coletividades, cuja ênfase está no vínculo e responsabilização com os usuários ${ }^{11}$.

No atual momento de desenvolvimento dos Cursos da Famema, em que já se espera ter caminhado na consolidação de um olhar ampliado das necessidades de saúde das pessoas, família e comunidade, considerando a diversidade e a complexidade do processo saúde/doença, por meio da VD, destaca-se como relevante conhecer os sentidos atribuídos pelos usuários a essa prática. A partir da visão do usuário pode-se analisar se a VD se constitui num caminho para formar os profissionais de saúde com uma nova visão do processo de saúde/doença, além da revelação das possíveis necessidades de ajuste. Além disso, acredita-se que os usuários desempenham papel significativo na interação entre a assistência prestada e os seus desejos e necessidades, vislumbrando a contínua melhoria da qualidade da atenção.

A partir dessa perspectiva, o presente estudo tem como objetivo analisar a ótica dos usuários de unidades de saúde da família sobre as visitas domiciliárias realizadas por estudantes de medicina e enfermagem de séries iniciais, no sentido de discutir o papel dessa tecnologia no processo educacional na produção do cuidado integral.

\section{Metodologia}

Trata-se de um estudo de abordagem qualitativa e fundamentada nos princípios da hermenêutica-dialética, realizado com usuários das Unidades de Saúde da Família (USFs) do município de Marília, onde os estudantes da primeira e da segunda série dos Cursos de Medicina e Enfermagem da Famema desenvolvem as atividades de prática profissional, por meio da VD.

A Famema é uma instituição estadualizada como autarquia vinculada à Secretaria de Estado da Saúde. Integram o complexo da Famema, além da unidade acadêmica, dois hospitais de ensino, um instituto de olhos, um ambulatório de especialidades e um hemocentro. Mantém também parceria com a Secretaria Municipal de Saúde (SMS) de Marília com a qual compartilha a estrutura e o processo de trabalho. A SMS conta atualmente com 12 Unidades Básicas de Saúde tradicionais (UBS) e 29 USFs, sendo que 20 das USFs existentes servem como campo de prática profissional para os estudantes da Famema. As 
USFs são instaladas em áreas onde a população apresenta maior carência socioeconômica, atendendo volta por $40 \%$ da população de Marília.

Os estudantes da primeira e da segunda série são inseridos nas USFs, em grupos de 12 , sendo quatro do Curso de Enfermagem e oito do Curso de Medicina e cada dupla de estudantes, composta preferencialmente por um da Enfermagem e um da Medicina, assume em torno de oito a dez famílias, as quais são acompanhadas no período de dois anos. Nestas séries os estudantes são supervisionados por um médico e um enfermeiro, sendo na maioria das vezes um deles da academia e o outro profissional do serviço. A seleção das famílias ocorre por indicação do Agente Comunitário de Saúde (ACS) que comunica previamente à família e, normalmente, acompanha a dupla de estudantes na primeira visita com a finalidade de fazer a apresentação. Os estudantes ao se apresentarem para as famílias explicam a finalidade do acompanhamento e solicitam o consentimento, deixando claro também o sigilo das informações coletadas. O médico e o enfermeiro supervisores da atividade revezam-se no acompanhamento das visitas, de forma que os estudantes ora vão sozinhos ora com a presença do supervisor. No retorno das visitas, as necessidades de saúde das famílias são discutidas no grupo, ocasião em que são pontuados os encaminhamentos necessários para a situação.

Para a coleta de dados foram selecionadas oito USFs que serviram de cenário de prática para tais estudantes, sendo duas de cada região da cidade (norte, sul, leste e oeste). A população do estudo foi constituída pelos usuários atendidos por meio das visitas domiciliárias. Na seleção dos usuários, buscou-se diversificar as características sociodemográficas, incluindo diferentes faixas etárias e classes socioeconômicas, bem como usuários sem e com agravos à saúde.

$\mathrm{Na}$ realização das entrevistas foram seguidos os seguintes princípios de amostra qualitativa: (a) escolher os sujeitos que detêm os atributos relacionados ao que se pretende estudar; (b) considerar tais sujeitos em número suficiente para que possa ter reincidência das informações; (c) considerar a possibilidade de inclusões sucessivas de sujeitos até que seja possível uma discussão densa das questões da pesquisa. Na constituição da amostra buscou-se uma representatividade que permitisse um aprofundamento da temática $^{12}$. A população do estudo foi constituída por 24 usuários, sendo três de cada unidade.

A coleta de dados deu-se por meio de entrevista utilizada como uma técnica de fonte de in- formação de dados primários, com perguntas semiestruturadas. Entrevista é "um processo de interação social entre duas pessoas na qual uma delas, o entrevistador, tem por objetivo a obtenção de informações da parte do outro, o entrevistado" ${ }^{13}$. As questões norteadoras referiam-se à opinião do usuário a respeito das visitas domiciliárias, pontos positivos, pontos negativos e sugestões. A mencionada coleta foi realizada por uma enfermeira com experiência na técnica de entrevista e que foi devidamente preparada pela coordenação da pesquisa. Essa profissional de saúde não teve nenhum contato prévio com as famílias. As entrevistas foram registradas em gravador digital e, posteriormente, transcritas.

Para a análise dos dados utilizou-se a perspectiva hermenêutico-dialética, tendo como referência os princípios do método de interpretação de sentidos, proposto por Gomes e colaboradores ${ }^{14}$, os quais se voltam para a interpretação do contexto, das razões e da lógica das falas, das ações, correlacionando os dados ao conjunto de inter-relações e conjunturas, dentre outros corpos analíticos.

A partir dessa perspectiva, foi realizada a leitura compreensiva das narrativas contidas na transcrição das entrevistas das famílias. Na sequência, foram identificadas as regularidades e as vivências singulares, por meio dos sentidos subjacentes às ideias descritas. Por último, elaborou-se uma síntese interpretativa, ancorada no confronto dos pontos de vista e das expressões das experiências dos atores. Nessa síntese, foram incorporadas, de forma crítica, as interpretações dos autores sobre aquelas produzidas pelos usuários procurando trazer maior visibilidade aos aspectos positivos e aos limites das VDs.

Esta pesquisa foi submetida à aprovação do Comitê de Ética e Pesquisa que Envolve Seres Humanos da Famema e todos os participantes foram esclarecidos a respeito do propósito da investigação e, para participar, assinaram o Termo de Consentimento Livre e Esclarecido.

Os trechos das entrevistas que ilustram os sentidos abstraídos foram codificados de acordo com o sexo (homem ou mulher), idade, unidade que pertence $(1,2,3,4,5,6,7$ ou 8$)$.

\section{Resultados e discussão}

No relato das famílias que recebem VDs dos estudantes da primeira e da segunda série dos Cursos de Enfermagem e de Medicina da Famema foram identificados sentidos que traduzem os 
aspectos positivos e os limites, bem como algumas recomendações.

\section{Os aspectos positivos das visitas domiciliárias percebidos pelos usuários}

$\mathrm{Na}$ ótica abstraída da fala dos usuários, os aspectos positivos da visita domiciliária referemse ao fato de os estudantes: ensinarem e aprenderem, buscarem e se preocuparem com a doença, trazerem respostas para os problemas, proporcionarem conversas e relações de afeto.

As VDs, quando possibilitam ensinar e aprender, na ótica das famílias, expressam os sentidos do ensino tanto pelo conhecimento específico que os estudantes apresentam como pela experiência de vida, revelando um aprendizado não só da escola como também a necessidade de as pessoas mais novas aprenderem com os mais velhos.

Quando elas [estudantes] começaram a me acompanhar, eu tava grávida e não sabia de nada, elas me ensinaram como amamentava... (mulher, 16 anos, U5)

A gente está por dentro de algumas coisas que eles [estudantes] não sabem [...] eles ensinam a gente e a gente também explica as coisas pra eles (Homem, 79 anos, U1).

...eles aprenderam com a gente e a gente aprendeu com eles, coisa que a gente não sabia [...] eu achei legal (mulher, 49 anos, U3)

Sobre a recorrência de que as visitas são espaços de aprendizagem, verifica-se que os usuários se sentem partícipes desse programa e, como decorrência disso, conseguem enxergar benefícios mútuos na relação estudantes-usuários, o que se aproxima do referencial da educação em saúde na perspectiva dialógica e remete à concepção de Freire de que ninguém se educa nem muito menos se liberta senão através de uma ação/produção cultural coletiva ${ }^{15,16}$.

Outro destaque pode ser dado ao fato dos depoimentos revelarem uma aproximação de classes sociais distintas. Assim, os estudantes da Famema, embora em sua maioria sejam oriundos das classes economicamente média e alta, conseguem estabelecer a comunicação, a empatia e o respeito nas relações com segmentos de classes populares.

O estabelecimento de relações dialógicas "entre os iguais e os diferentes" é considerado "componente fundante" da educação, especialmente da popular ${ }^{16}$. A comunicação entre duas visões de mundo leva à produção de significados de ambos os grupos sociais, e a cultura de cada um estará igualmente sempre presente, sendo que o sucesso desse processo depende da negociação com uma postura receptiva entre as partes ${ }^{17}$. Nesta perspectiva, para que ocorra a troca de experiências é preciso ir além do reconhecimento da diversidade subjetiva, as relações precisam deslocar-se no sentido da horizontalidade, permitindo entender as peculiaridades subjetivas das pessoas, no sentido de sua origem e possível mobilidade ${ }^{18}$.

A importância dessa compreensão, com vista a desencadear uma lógica de atenção à saúde pautada na noção de sujeito, é enfatizada tanto nas diretrizes curriculares nacionais para os Cursos de Enfermagem e Medicina como no Projeto Pedagógico dos Cursos em questão.

Os aspetos positivos das VDs também se afirmam nas falas pelo fato de os estudantes darem atenção, proporcionarem conversas e relações de afeto, conforme falas seguintes:

Adorei eles [estudantes] porque eles dá atenção pra gente, orienta tudo... (Mulher, 49 anos, U3)

[As visitas são boas porque podemos] conversar, falar sobre os problemas, das alegrias, das tristezas. [A visita] ajudava a gente a pensar no que estava acontecendo aqui em casa. Eu gosto bastante... (Mulher, 41 anos, U3).

Eu acho que eles [estudantes] têm muita educação para lidar com o povo porque pra cuidar do povo tem que ser atencioso mesmo (Mulher, 62 anos, U3).

Inscreve-se, assim, a lógica do dialogo no desenvolvimento da educação problematizadora que prepara para a captação e para a intervenção no mundo, através do respeito e da valorização dos atos de fala de cada sujeito participante do processo $^{16}$. Para Paulo Freire, o diálogo é condição essencial para os sujeitos atingirem um estágio de consciência devotada à responsabilidade política e social ${ }^{15}$. Para o sucesso do diálogo é preciso compartilhamento e reconhecimento das linguagens, culturas, sensos comuns, iniciando pela adequação da linguagem profissional técnica, para que esta não domine o contexto da intersubjetividade $^{18}$. Acrescenta-se que no encontro intersubjetivo e na atenção individualizada colocam-se em cena peculiaridades do universo afetivo, cultural e social dos sujeitos e dos agentes da ação cuidado$\mathrm{ra}^{18}$. Desta forma, pode-se depreender a possibilidade da criação de vinculo e, consequentemente, de adesão aos cuidados de saúde.

Considerar que os estudantes trazem respostas para o problema aparece na fala dos usuários com o sentido de resolução de um problema ou de uma demanda. Esse sentido pode ser ilustrado nos seguintes depoimentos: 
Eu também perguntei sobre como fazer para o meu marido fazer a vasectomia, mas aí eles [estudantes] foram atrás e viram que nós não íamos conseguir (Mulher, 25 anos, U1).

$\mathrm{Se}$ [...] estou com algum problema, elas [estudantes] vão lá falar com o doutor e voltam para dar a resposta (Mulher, 25 anos, U2).

Nas VDs realizadas pelos estudantes pode-se depreender que elas possibilitam a ampliação do acesso aos serviços de saúde pela identificação das necessidades de saúde da família e seu encaminhamento, o que se encontra em conformidade com as diretrizes da ESF. O reconhecimento da importância e da eficácia da VD relacionase com o fortalecimento do vínculo, a relação de confiança e o compromisso estabelecido entre a equipe e a família ${ }^{4}$. Assim, como afirmam Mandú et al. ${ }^{10}$, a VD proporciona a integralidade e o acesso da população ao serviço de saúde, contribuindo, desta forma, para se atingir a proposta de mudança no modelo de atenção à saúde.

Enquanto dimensão da integralidade, a boa prática profissional consiste em dar uma resposta ao sofrimento do usuário e em um cuidado que não seja reduzido ao seu aparelho ou sistema biológico. Deste modo, a integralidade está presente no encontro, na conversa, na atitude dos profissionais, ao reconhecer que as necessidades de saúde vão além das demandas explicitas ${ }^{19}$.

No que se refere à busca e à preocupação com a doença, as falas dos usuários apontam os seguintes sentidos: medir pressão, descobrir um problema, examinar, verificar se tomam o remédio direito e apressar os exames na unidade. Os depoimentos abaixo ilustram esses sentidos:

Vinham aqui, faziam perguntas, media a pressão da gente... (Mulher, 73 anos, U6)

Eu acho que contribuiu. [Os estudantes] ajudaram bastante... Começaram em mim, aí passou pelos meus filhos e meu marido. Todo mundo foi examinado por eles... Dava as orientações para nós certinho (Mulher, 49 anos, U3).

Eles [estudantes] controlavam também os remédios pra ver se tava errado (Mulher, 49 anos, U3).

Eu tinha alguns exames para colher no posto $e$ demorava bastante. Eles [estudantes] vindo aqui apressavam mais os meus exames (Mulher, 25 anos, U1).

Essas opiniões dos usuários, de certa forma, reduzem o papel da VD a problemas relacionados somente a doenças. Essa redução se verifica, principalmente, quando os entrevistados respondem sobre as suas condições de saúde. Em suas respostas, observa-se sempre uma relação com a resolução de doenças ou a ausência delas. Essa recorrência da doença pode refletir uma prática que por muitos anos se perpetuou no interior dos serviços de saúde, a qual se centra muito mais nos agravos do que na promoção de saúde e na prevenção de doenças.

Evidencia-se, assim que o modelo de atenção à saúde centrado na doença também se encontra presente no imaginário dos usuários, sendo possível que essa forma de pensar contribua sobremaneira com os entraves encontrados nas propostas de mudanças. Assim, torna-se ainda mais evidente a importância desse encontro usuáriosestudantes, na medida em que propicia a ambos uma vivência que ultrapassa a preocupação com a doença e revela que a escuta, o vínculo, a responsabilização e a troca de informações são condições essenciais para a melhoria das condições de saúde. Nos aspectos relacionados a VD, no âmbito da Estratégia da Saúde da Família, o estudo que avalia a percepção dos usuários confirma a importância da empatia e do vínculo como elementos centrais na relação, bem como a humanização do cuidado ${ }^{8}$.

Destaca-se também no segundo depoimento o fato de os estudantes terem preocupação com toda a família e não só com um de seus membros. Isso reforça a proposta curricular e os princípios dos SUS, que caminham na direção de se promover uma integralidade das ações de saúde.

Observa-se, no conjunto dos depoimentos dos usuários, que os eixos reveladores de uma VD que atende às necessidades das famílias, em alguns aspectos, aproximam-se da proposta pedagógica da Famema, uma vez que esses sujeitos valorizam a possibilidade de ouvir e de ser ouvido, de resolução de problemas, de ensinar e aprender e de desenvolver relações afetivas. Esses aspectos, de certa forma, revelam que os princípios curriculares estão sendo trabalhados na formação profissional dos estudantes. Além disso, há evidências de que a organização curricular caminha no sentido de atender às necessidades de saúde da população.

Junto a isso, os sentidos apontados pelos entrevistados como inerentes às VDs realizadas pelos estudantes corroboram com a consideração de que estas são um instrumento ideal para a educação em saúde, pois a troca de informação se dá no contexto de vida do indivíduo e de sua família, o que torna possível adequá-las à singularidade da situação vivenciada ${ }^{20}$.

A direcionalidade dada aos currículos dos Cursos de Enfermagem e de Medicina no desenvolvimento de atividades em cenários reais implica tanto a aprendizagem como o cuidado efe- 


\section{Limites das visitas domiciliárias percebidos pelos usuários}

No conjunto dos depoimentos dos usuários destacam-se, como limites, a falta de preparo para lidar com a doença, a alteração da rotina cotidiana dos usuários por conta das visitas e o não cumprimento do planejamento da visita.

A falta de preparo para lidar com a doença é expressa na ótica dos usuários como um limite das visitas, visto que os estudantes têm pouco tempo de vivência profissional. Tal sentido encontra-se na fala seguinte:

De doença eles ainda não descobriram nenhuma em mim porque eles são novo (Mulher, 59 anos, U2).

A fala dessa entrevistada reincide na expectativa do cuidado centrado na doença, porém, ao se comparar tal expectativa com a concepção curricular no que tange às visitas, observa-se que o limite do não preparo para lidar com a doença necessariamente não se configura como um fragilidade, uma vez isso não constitui tarefa para os estudantes das séries iniciais.

Os usuários apontam como limite da VD a alteração da rotina cotidiana por conta das visitas, o que se encontra expresso nas descrições que seguem:

Só que de vez em quando eu tava ocupada ou tinha acabado de acordar, mas eles não reparavam (Mulher, 41 anos, U3).

Quando eu tava ocupada, eu não gostava muito que eles [estudantes] aparecia. Mulher, 78 anos, U2)

As famílias, desta forma, parecem reivindicar certa garantia à sua intimidade. Esses limites apontados pelos usuários são discutidos em outros estudos referentes à $\mathrm{VD}^{22}$ e merecem ser considerados no contexto da atenção à saúde, por demandarem dos profissionais claro reconhecimento do modo de vida das pessoas, além de envolver o estabelecimento de vínculo.

A falta de cumprimento do planejamento da VD pelos estudantes, revelada nas falas dos usuários, parece causar desapontamento, conforme segue.

Eles [estudantes] marcaram de vir aqui na quinta e não vieram mais (Mulher, 62 anos, U3). ...eram muito bonzinhos [estudantes], foram embora sem se despedir porque não deu tempo. (Mulher, 73 anos, U6).

Os limites apontados podem ser foco de discussões acerca da melhor forma de organizar e de desenvolver visitas domiciliárias mais próximas da realidade das famílias. Além disso, indicam que é preciso avançar no reconhecimento das necessidades das famílias, o que é possível por meio de vínculos efetivos.

Embora a visita domiciliária represente uma tecnologia utilizada nos diferentes momentos da evolução histórica da atenção à saúde brasileira, os problemas relacionados com a mesma sempre foram motivo de preocupação. Por um lado, encontram-se os aspectos culturais dos usuários/famílias e de outro a formação dos trabalhadores e seu preparo para adentrar no domicílio das famílias. Neste contexto, afirma-se que ao considerar como invasão de privacidade a presença do profissional no ambiente do domiciliário, denota-se a possibilidade de um cenário de imposição do conhecimento profissional, sem o devido respeito às crenças e aos valores das famílias $^{23}$. Entretanto, numa formação profissional de saúde ancorada na perspectiva dialógica, essas preocupações devem ser objeto do próprio processo de aprendizagem dos futuros profissionais para que possam exercitar o diálogo de saberes e a negociação entre lógicas distintas voltadas para os cuidados em saúde.

\section{As recomendações dos usuários}

Os usuários que receberam VDs dos estudantes, de maneira geral, apontam para recomendações que indicam a satisfação com o atendimento recebido, ao relatar que mais famílias deveriam receber o atendimento dos estudantes, conforme se observa a seguir:

...acompanhar bastante família porque tem bastante família com gente acamada, que tem bastante necessidade destas visitas, até pra ter uma informação... (Mulher, 44 anos, U6).

...Acho bom eles [estudantes] estarem passando em outras casas, tem gente que precisa mais que eu aqui (Mulher, 27 anos, U8).

Ao indicar a visita, os usuários mais uma vez mencionam a visão da doença e a incapacidade como objeto de trabalho dos profissionais de saúde. Esta visão, por um lado, pode demonstrar que eles ainda não incorporam o papel do profissional voltado para promover a saúde, com vistas a uma melhor qualidade de vida. Por outro lado, merece consideração o papel hegemônico 
dos profissionais da saúde na condução do processo de adoecimento, não sendo possível negar sua relevância. Além disso, a consciência da necessidade de prevenção é ...uma experiência mediatizada pela teoria, o que não corresponde à experiência existencial da maioria de nossa população ${ }^{24}$.

Apesar do que foi citado nas recomendações, fica claro no decorrer deste estudo, assim como em outro que analisa a percepção dos usuários sobre o processo saúde-doença que a população espera do serviço de saúde, um cuidado que ultrapasse as ações voltadas ao corpo biológico, sendo a relação profissional-usuário destacada no julgamento da qualidade do atendimento ${ }^{24}$. Nessa perspectiva, apesar de o discurso médico ser incorporado na fala dos sujeitos, ultrapassa-se a dimensão biológica do processo saúde-doença, na medida em que se leva em conta aspectos como as relações sociais e afetivas envolvidas neste processo, aspectos que podem ser exercitados na VD.

\section{Considerações finais}

No presente estudo, ao se propor analisar o sentido da VD realizada pelos estudantes da primeira e da segunda séries dos Cursos de Enfermagem e de Medicina, na ótica dos sujeitos, há de ser considerado que os usuários atendidos pelos alunos foram aqueles que aceitaram tal acompanhamento, após informados sobre o que seria realizado e solicitada autorização para esse fim. Além disso, os estudantes foram apresentados para os usuários, na maioria das vezes, pelo ACS, com quem eles já mantêm vínculo. Esse fato demonstra que para o acompanhamento das famílias já havia uma predisposição para a aceitação, o que pode ter contribuído para uma avaliação satisfatória das mesmas. No entanto, ao remeter ao objeto de estudo, interessa o reconhecimento dos sentidos atribuídos pelos usuários às visitas dos estudantes, enquanto instrumento que visa contribuir, no âmbito do SUS, com a proposta de atendimento integral e humanizado.

Nesta perspectiva, na presente investigação encontram-se elementos que retratam as expectativas dos usuários em relação ao cuidado à saúde, pois ao mesmo tempo que reproduzem a visão centrada na doença indicam um conjunto de atributos que vão além do cuidado a um corpo biológico, incluindo a importância das relações interpessoais no contexto da atenção à saúde, a necessidade da escuta, da atenção, da orientação e da preocupação em dar respostas e encaminhamentos para as necessidades identificadas.
Assim, compreende-se que o direcionamento dado ao currículo ao utilizar a VD como uma forma de aproximação com o usuário, contribui para desenvolver a interação e para a compreensão do seu contexto de vida.

Frente a isto, ao considerar que a formação profissional encontra-se na pauta das necessidades a serem enfrentadas na mudança de modelo de atenção, pode-se visualizar características importantes que transcendem a lógica do atendimento voltado para a doença e centrado na queixa principal de ordem biológica. Evidenciam-se também predicativos de ações inerentes ao princípio da humanização e do cuidado centrado no usuário e sua família.

Sendo assim, é possível que esta visão contribua para o desenvolvimento de ações com base na complexidade do processo saúde-doença e para desvelar o caminho para se assumir o principio da integralidade, especialmente na dimensão da boa prática profissional, como um orientador das práticas em saúde e da formação profissional.

Os limites da VD identificados nas falas dos usuários, por outro lado, apontam para a necessidade de maior organização e planejamento dela, visando a não desapontá-los ou a não incomodá-los na rotina diária.

Por último, cabe ressaltar a importância do contínuo aperfeiçoamento dessas ações, tanto no que se refere a seu planejamento como no reforço de atitudes respeitosas e humanizadas ao longo do curso, além de implementar ações que reforcem a integralidade do cuidado com vistas a imprimir uma nova lógica de atenção à saúde.

\section{Colaboradores}

MJS Marin participou da coordenação do projeto e na justificativa, definição metodológica, análise dos dados e considerações finais. R Gomes orientou a definição do referencial de análise, a análise dos dados e considerações finais. AC Siqueira Junior, CRR Nunes; CP Cardoso, MP Otani e MY Moravcik participaram igualmente na definição metodológica, coleta de dados, análise dos dados e considerações finais. 


\section{Referências}

1. Brasil. Ministério da Saúde (MS). Secretaria de Atenção à Saúde. Departamento de Atenção Básica. Política nacional de atenção básica. Brasília (DF): Ministério da Saúde (MS); 2007.

2. Brasil. Ministério da Saúde (MS). Secretaria de Assistência à saúde. Coordenação de Saúde da Comunidade. Saúde da família: uma estratégia para reorientação do modelo assistencial. Brasília (DF): Ministério da Saúde (MS); 1998.

3. Sakata NK, Almeida MCP, Alvarenga AM, Craco PF, Pereira MJB. Concepções da equipe de saúde da família sobre as visitas domiciliares. Rev Bras Enf 2007; 60(6):659-664.

4. Omizzolo JAE. O princípio da integralidade na visito domiciiar: um desafio ao enfermeiro do Programa de Saúde da Família [dissertação]. Florianópolis: Universidade Federal de Santa Catarina; 2006.

5. Takahashi RF, Oliveira MAC. A visita domiciliária no contexto da saúde da família. In: Instituto para o Desenvolvimento da Saúde (IDS), Universidade de São Paulo (USP), Ministério da Saúde, Fundação Telefônica. Manual de enfermagem. São Paulo: Instituto para o Desenvolvimento da Saúde (IDS); 2001. p. 43-46.

6. Lopes WO, Saupe R, Massaroli A. Visita domiciliar: tecnologia para o cuidado, o ensino e a pesquisa. Cienc Cuid Saúde 2008; 7(2):241-247.

7. Paugan S. Desqualificação social: ensaio sobre a nova pobreza. São Paulo: Cortez; 2003.

8. Albuquerque ABB, Bosi MLM. Visita domiciliar no âmbito da Estratégia Saúde da Família: percepções de usuários no Município de Fortaleza, Ceará, Brasil. Cad Saude Publica 2009; 25(5):1103-1112.

9. Souza CR, Lopes SCF, Barbosa MA. A contribuição do enfermeiro no contexto de promoção à saúde através da visita domiciliar. Rev da UFG 2004; 6(n ${ }^{\circ}$ especial). [acessado 2011 set 20]. Disponível em: http://www.proec.ufg.br/revista_ufg/familia/G_ contexto.html

10. Mandú ENT, Gaiva MAM, Silva MA, Silva AMN. Visita domiciliária sob o olhar do usuário do Programa de Saúde da Família. Texto \& Contexto Enferm 2008; 17(1):131-140.

11. Faculdade de Medicina de Marília (Famema). Manual de avaliação do estudante: Cursos de Medicina e Enfermagem. Marília: Famema; 2006.

12. Minayo MCS. O desafio do conhecimento: pesquisa qualitativa em saúde. 5a ed. São Paulo: Hucitec; 1998.

13. Haguette TMF. Metodologias qualitativas na sociologia. 4a ed. Petrópolis: Vozes; 1995.

14. Gomes R, Souza ER, Minayo MCS, Malaquias JV, Silva CFR. Organização, processamento, análise e interpretação dos dados: o desafio da triangulação. In: Minayo MCS, Assis SG, Souza ER, organizadores. Avaliação por triangulação de métodos: abordagem de programas sociais. Rio de Janeiro: Editora Fiocruz; 2005. p. 185-221.
15. Freire P. Educação como prática da liberdade. Rio de Janeiro: Editora Paz e Terra; 1984.

16. Costa ARF. Precisa a educação (popular) ser dialógica(?) [Internet]. In: $V$ Colóquio Internacional Paulo Freire; 2005 set 19-22; Recife. Recife; UFPE, 2005. [acessado 2009 jul 15]. Disponível em: http:// www.paulofreire.org.br/pdf/comunicacoes_orais/ PRECISA\%20A\%20EDUCA\%C3\%87\%C3\%83O\%20 POPULAR\%20SER\%20DIAL\%C3\%93GICA.pdf

17. Oliveira FA. Antropologia nos serviços de saúde: integralidade, cultura e comunicação. Interface $\mathrm{Co}$ mun Saúde Educ 2002; 6(10):63-74.

18. Mandú ENT. Intersubjetividade na qualificação do cuidado em saúde. Rev Latinoam Enferm 2004; 12(4):665-675.

19. Mattos RA. Os sentidos da integralidade: algumas reflexões acerca de valores que merecem ser defendidos. In: Pinheiro R, Mattos RA, organizadores. Os sentidos da integralidade na atenção e no cuidado á saúde. Rio de Janeiro: IMS, ABRASCO; 2001. p. 39-64.

20. Ferraz L, Aerts DRGC. O cotidiano de trabalho do agente comunitário de saúde no PSF em Porto Alegre. Cien Saude Colet 2005; 10(2):347-355.

21. Faculdade de Medicina de Marília (Famema). Necessidades de Saúde - $1^{a}$ e $2^{a}$ série: Cursos de Medicina e Enfermagem. Marília: Famema; 2007.

22. Mazza MMPR. A visita domiciliária como instrumento de assistência de saúde. Rev Bras Crescimento desenvolv Hum 1994; 4(2):60-68.

23. Santos EM, Kirschbaum DIR. A trajetória da visita domiciliária no Brasil: uma revisão bibliográfica. Rev Eletr Enferm [periódico na Internet]. [acessado em 2009 out 27]; 10(1): [cerca de 8p.]. Disponível em: http://www.fen.ufg.br/revista/v10/n1/v10n1a20.htm

24. Bosi MLG, Affonso KC. Cidadania, participação popular e saúde: com a palavra, os usuários da rede pública de serviços. Cad Saude Publica 1998; 14(2):355-365.

Artigo apresentado em 18/11/2009

Aprovado em 15/12/2009

Versão final apresentada em 19/12/2009 
